\title{
Intentions on contraception use and its associated factors among postpartum women in Aksum town, Tigray region, northern Ethiopia: a community-based cross- sectional study
}

\author{
Teklehaymanot Huluf Abraha ${ }^{1 *}$ (D) Hailay Siyum Belay ${ }^{1}$ and Getachew Mebrahtu Welay ${ }^{2}$
}

\begin{abstract}
Background: Increased access to contraceptive methods has been established as a cost-effective strategy for developing countries to reduce maternal and child mortality. Intentions to contraceptive uptake appear to be best predictors of actual contraceptive practice than the unmet need. However, intention to contraceptive use in Ethiopia particularly among postpartum women is not well assessed. Therefore, the objective of this study was to assess intention to use modern contraceptive and to identify factors associated among postpartum women in Aksum town.

Methods: A community -based analytical cross-sectional study design was done to collect the data from 604 postpartum mothers using a structured questionnaire. The data was collected from March 25 to April 24, 2015. A multivariable logistic regression was conducted to assess factors associated with intentions to use contraceptive methods. Factors influencing intentions on contraceptive methods use were assessed by computing adjusted odds ratios (AOR) at 95\% confidence interval (Cl) with statistical significant $p$-value $<0.05$.

Results: Intention to use modern contraceptive was $84.3 \%$. Resumed sexual intercourse (AOR $=1.78 ; 95 \% \mathrm{Cl}: 1.34,3.92$ ) and women whose their husband approved family planning to use ( $A O R=1.57 ; 95 \% \mathrm{Cl}: 2.02,5.57)$ were more likely to have intention on contraceptive use. In addition, those women who knew at least one method of modern contraceptive $(A O R=5.17 ; 95 \% \mathrm{Cl}: 1.69,15.82)$ were more likely to had intention to use modern contraceptive during extended postpartum period compared to their counterparts.

Conclusion and recommendation: More than eight in ten study participants have intention to use contraceptive in the Aksum town. Resumed sexual intercourse, husband's approval of family planning and knew at least one method of contraceptive are the three major predictors to be an areas when considering interventions to increase of intention on contraceptive. Therefore, this study highlighted that; in order to increase intention and adoption of contraceptive, the family planning services providers and programmers should continue the promotion of partner involvement and increasing family planning knowledge through printed media and mass media.
\end{abstract}

Keywords: Contraceptive use, Intention, Postpartum period, Factors, Aksum, Tigray, Ethiopia

\footnotetext{
*Correspondence: teklehaymanothuluf@gmail.com

${ }^{1}$ Department of Reproductive Health, School of Public Health, College of Health Sciences, Aksum University, P.O. Box: 298, Aksum, Tigray, Ethiopia Full list of author information is available at the end of the article
}

(c) The Author(s). 2018 Open Access This article is distributed under the terms of the Creative Commons Attribution 4.0 International License (http://creativecommons.org/licenses/by/4.0/), which permits unrestricted use, distribution, and reproduction in any medium, provided you give appropriate credit to the original author(s) and the source, provide a link to the Creative Commons license, and indicate if changes were made. The Creative Commons Public Domain Dedication waiver (http://creativecommons.org/publicdomain/zero/1.0/) applies to the data made available in this article, unless otherwise stated. 


\section{Plain English summary Background plain}

Family planning is an integral component of Maternal and Child Health $(\mathrm{MCH})$ services in the Ethiopia health system. However, unmet need of contraceptive during Extended Postpartum Period in Ethiopia is unacceptable high. This exposes the mothers to high risk of unwanted pregnancies and unsafe abortion. This study is the first to assess the level of intention on contraception among postpartum women in Ethiopia, particularly in the study area. Measuring the prevalence of intention for contraception in the extended postpartum period is pivotal for designing and evaluating postpartum family planning programs. Finding from this study could help family planning planners and services providers to have a good insight of predictors of intention on contraceptive adoption and to take necessary interventions.

\section{Methods}

Between March 25 to April 24, 2015, was conducted a study among 604 postpartum women in Aksum town, Tigray region, northern Ethiopia. We conducted analytical cross- sectional study design using a systematic random sampling technique. A structured item questionnaire was used to collect data on the socio-demographic, knowledge of mother regarding family planning, maternal and reproductive health related variables. Data cleaning and analysis was carried out with the aid of IBM Statistical Package for the Social Sciences (SPSS) version 20 for Windows. Descriptive analysis was used to explore the characteristics of the study participants.

\section{Results}

Majority of study participants intended to use contraceptive during the Extended Postpartum Period (EPP). Women who resumed sexual intercourse, husband approved family planning to adopt and know at least one method of contraceptive were identified factors associated with intention to use contraceptive.

\section{Conclusion and recommendation}

Despite the fact that majority of postpartum women was intended to use, but the level of contraceptive adoption found low (48\%). Therefore, in order to increase intention and adoption of contraceptive husband/partner involvement is mandatory.

\section{Background}

Contraceptive utilization is a key predictor in preventing unwanted pregnancies, reducing maternal and child mortality, and improving the lives of women and their families $[1,2]$. In addition, it is critical in achieving towards the 2030 Sustainable Development Goals (SDGs) [3]. Intention to use postpartum modern contraceptive methods is a better measurement for contraceptives in the extended postpartum period than the unmet need. In addition, by expressing the intention to use contraception, women are able to better visualize their future need and are more likely to translate it in to actual practice $[4,5]$.

Extended Postpartum Period (EPP) provides a window of opportunity for women on the adoption of modern contraceptive methods [6-8]. Despite the fact that, in developing countries many postpartum women fail to obtain family planning services soon after birth and become pregnant again, either much sooner than they wish or contrary to their desire to cease child bearing entirely [5].

A study conducted in 21 low and middle income countries found that $90 \%$ of postpartum women intended to adopt contraceptive in future [5]. In United State of America (USA), the proportion of women who expressed an intention to use modern contraceptive methods was estimated 91\% [9]. Research evidence have showed that, maternal age, antenatal care service use, prior use of any contraceptive use [10], knew at least one contraceptive method [11] had been identified as factors associated for intention to use contraceptive.

About 86\% of women in Ethiopia have an unmet need for family planning methods in the Extended Postpartum Period (EPP) [6]. Each year, 1.9 million Ethiopian women had an intended pregnancy. In Tigray, contraceptive utilization among postpartum women is low [12, 13]. Federal Ministry of Health set an objective to increase family planning adoption from 42 to $55 \%$ by 2020 [14]. Among the general population, the factors affecting women's intentions to adopt contraception methods had been studied extensively [11, 15-18]. However, intention on contraceptive use in Ethiopia among postpartum women is a great limitation of the literature. Therefore, the objective of this study was to file these gaps and to assess intention to use modern contraceptive and identifying determinant factors among postpartum women in Aksum town. The finding from this research project could help planners, programmers, nongovernmental organizations (NGOs) and decision makers to have a good insight of factors intention on contraceptive utilization and to take appropriate interventions and may result in steeper increase in the uptake of family planning methods and a reduction in maternal mortality, child mortality, infant, neonatal mortality and unintended pregnancies rate.

\section{Methods}

\section{Study design and study setting}

A community-based cross-sectional study design was carried out between March 25 to April 24, 2015 in Aksum town, Tigray region. According to [19], the town administrative health office report the estimated total population 60,706 , of whom 30,960 are women living in five kebeles (the smallest administrative unit). Majority 
of the population depends on none agriculture production. The town has achieved universal health coverage. There are 2 public Health Centers, 1 referral hospital (owned by Aksum University), 1 Zonal Hospital, 5 private clinics and 11 drug shops providing maternal, child and other health services to the population.

\section{Sources population}

All reproductive age women who gave birth in the last 12 months prior to the study period (March 25, 2015-April 24, 2015) and who lived in Aksum town for more than 6 months were taken as sources population.

\section{Study population}

All reproductive age women who gave birth in the last 12 months during the data collection period (March 25, 2015- April 24, 2015) in the randomly selected kebeles.

\section{Inclusion criteria}

The study target women who had gave birth in the last 12 months, regardless of parity, ethnicity, religion, income, education, maternal age, maternal health services, sexual activities, menses status, knowledge of contraception and use were included.

\section{Exclusion criteria}

Women who were unable to speak or not hearing, those who had a still birth and/or neonatal deaths with the previous pregnancy and hysterectomy.

\section{Sample size and sampling technique}

A single population proportion formula was used to determine the sample size considering the following assumptions: Since there is no a study in Ethiopia, the proportion women who have intentions on contraception use methods in extended postpartum period was assumed to be $50,95 \% \mathrm{CI}, 5 \%$ absolute level of precision $[20,21]$, and $1.5 \%$ design effect. In addition a none response rate 5\% was used and finally a sample size of 604 was determined. From the four kebele in Aksum town, two kebele were selected using a lottery method. The samples size was allocated by using proportional allocation to size (PAS) to the total number of postpartum women in the kebeles. A total of 604 study participants were selected by systematic random sampling technique (Additional file 1. Figure S1). Before the data collection; all eligible study participants who gave birth within the past 1 year in the randomly selected kebeles were traced using house-to-house survey.

\section{Operational definition and definition of terms Intention to use a modern contraception}

Intention to use a modern contraception refers to all women who were found in the extended postpartum period who are not currently using any modern contraception but reporting intent to use any of modern contraceptive at some time in the future. A binary dependent variable indicating intention use any method of the modern contraceptive coded as "1" and no intention coded as " 0 ".

\section{Knowledge of modern contraceptives}

Knowledge of modern contraceptives refers to the study participants' spontaneously mentioned at least one of the modern contraceptives (pills, injectable, implants, IUD, female and male sterilization) [22].

\section{Extended Postpartum Period (EPP)}

The first-twelve month period after a live birth [7].

\section{Birth interval}

It is the length of time between two successive live births [23].

\section{Parity}

The number of children ever given birth.

\section{Want space}

Are those who are fecund (able to become pregnant) but want to postpone their next birth for 2 or more years [24].

\section{Want to limit}

Are those who are fecund (able to become pregnant) but are saying they do not want another child [24].

\section{Data collection}

Data was collected via face to face interview at the study participant's home using a structured and pre-tested questionnaire. The tool was prepared originally in English and translated to local language (Tigrigna) and translated back to English in order to maintain internal consistency. The tools was adopted from similar studies [9, 10], but customized for this study. The questionnaire included sections on socio demographic characteristics of respondents, their maternal health service use, their reproductive intentions, their knowledge and current adoption and their intentions to use contraceptive methods among postpartum women. Four female diplomas Midwifery and one BSc Nurse were participated in the data collection process. They had given 2 days training before deploying to actual work. The supervisors and the principal authors supervised the data collection process and checked the data completeness on daily bases.

\section{Statistical analysis}

Data were entered and cleaned using EPI-Info version 7(Centers for DiseaseControl and Prevention, Atlanta, GA, USA) [25] and exported to SPSS version 20 (SPSS 
Inc., Chicago, IL, USA) for analysis. Descriptive statistics were done presented in the form of tables and texts. Both binary and multiple logistic regressions were carried out to identify associated factors. The explanatory variables $(p<0.2)$ were then further analyzed by logistic regression. Factors influencing to intentions on contraceptive methods use were assessed by computing adjusted odds ratios(AOR) at 95\% confidence inter$\operatorname{val}(\mathrm{CI})$ with statistical significant $p$ - value $<0.05$. The final model was assessed for multicolliniarity using Variance Inflation Factor(VIF) [26] and goodness of fit using Hosmer and Lemishow test [27].

\section{Results}

\section{Socio-demographic variables}

In this study, 604 postpartum women were interviewed. From these, 590(97.7\%) women were responded to the questioner. The mean age of the study participants was $27.4 \pm 5.0$ years. Two hundred thirty one (39.2\%) were aged between 25 and 29 years; $3.2 \%$ were teenagers ( $<20$ years). Three hundred eighty three (64.9\%) were housewives. Almost all (99.3\%) were Tigray by ethnicity, the rest were Amhara. Of the respondents, 546 (92.5\%) were Orthodox Tewohado Christians, and the rest were Muslim. Three hundred eight (52.2\%) of the study participants had attended secondary and above educational level and $38.5 \%$ of their partner attended primary educational school (Table 1).

\section{Maternal and reproductive health services use}

In this study a total 579 or $98.1 \%$ of the study participants attended at least one antenatal care (ANC) visits. Furthermore, 85 and $13.1 \%$ of the study participants received antenatal care from hospital and health centers respectively. Five hundred twenty four of the women had received four or more antenatal care visits. Five hundred seventy seven delivered by skill attendants at health institution (Health Center or Hospital). Two hundred fifty eight $(43.7 \%)$ had received postnatal care (PNC) either at health center or hospital. Among all women $68.3 \%$ of them had resumed sexual intercourse at the time of survey. One hundred fifty nine (39.45\%) of the study participants start sexual intercourse at 6 week of postpartum period. More than three forth (77.5\%) of women got family planning counseling in their home by the town health extension workers (HEWs) in the last 12 months. Two hundred eighty three (48\%) study participants were using modern contraceptive (Table 2).

\section{Intentions on modern contraceptive use methods in the extended postpartum period}

The prevalence of intention to use modern contraceptive was $84.3 \%$. Of those who had intentions, $215(83.3 \%)$ and
Table 1 Socio- demographic variables in Aksum town, Tigray region, northern Ethiopia, June, 2015

\begin{tabular}{|c|c|c|}
\hline Variables & Frequency $(\mathrm{n})$ & Percentage (\%) \\
\hline \multicolumn{3}{|l|}{ Age } \\
\hline $16-19$ & 19 & 3.2 \\
\hline $20-24$ & 149 & 25.2 \\
\hline $25-29$ & 231 & 39.2 \\
\hline $30-34$ & 126 & 21.4 \\
\hline $35-49$ & 65 & 11.0 \\
\hline \multicolumn{3}{|l|}{ Marital status } \\
\hline Married & 543 & 92.0 \\
\hline Others $^{\mathrm{a}}$ & 47 & 8.0 \\
\hline \multicolumn{3}{|l|}{ Educational status } \\
\hline No formal education & 80 & 13.6 \\
\hline Primary education & 202 & 34.2 \\
\hline Secondary education and above & 308 & 52.2 \\
\hline \multicolumn{3}{|l|}{ Partner's education $(n=545)^{\mathrm{b}}$} \\
\hline No formal education & 24 & 4.4 \\
\hline Primary school & 210 & 38.5 \\
\hline Secondary school and above & 311 & 57.1 \\
\hline \multicolumn{3}{|l|}{ Mother occupation } \\
\hline House wife & 383 & 64.9 \\
\hline Government employee & 46 & 7.8 \\
\hline Private employee & 103 & 17.5 \\
\hline Daily labourer & 43 & 7.3 \\
\hline Others $^{c}$ & 15 & 2.5 \\
\hline \multicolumn{3}{|l|}{ Partner occupation $(n=545)^{\mathrm{b}}$} \\
\hline Government employee & 125 & 22.9 \\
\hline Private employee & 257 & 47.2 \\
\hline Daily labourer & 131 & 24.0 \\
\hline Others $^{\mathrm{d}}$ & 32 & 5.9 \\
\hline \multicolumn{3}{|l|}{ Monthly income (Ethiopian Birr) } \\
\hline$\leq 600$ & 150 & 25.4 \\
\hline $601-1000$ & 159 & 26.9 \\
\hline $1001-2000$ & 154 & 26.1 \\
\hline$\geq 200$ & 17 & 21.5 \\
\hline
\end{tabular}

${ }^{\mathrm{a}}$ Single, separated, divorced, or widowed

${ }^{\mathrm{b}}$ Among married women

'Alcohol /Swa seller, farmer, or student

${ }^{d}$ Farmer, pension, or guard

43(16.7\%) had intentions to adopt for purpose of spacing and limiting respectively. Nearly two third (66.4\%) of the study participants used modern contraceptive prior to the last child. Regarding knowledge of modern contraceptive almost all $95.8 \%$ of the postpartum women were found that knowledgeable on the modern contraceptive methods. The least mentioned type of modern contraceptive use was male and female sterilization (Table 3). 
Table 2 Characteristics of maternal and reproductive health services use in Aksum town, Tigray region, northern Ethiopia, June, $2015(n=590)$

\begin{tabular}{lll}
\hline Variables & Frequency $(\mathrm{n})$ & Percentage $(\%)$ \\
\hline Parity $(n=590)$ & & \\
$1-4$ & 536 & 90.8 \\
$>=5$ & 54 & 9.2 \\
Currently living children $(n=590)$ & & \\
1 & 182 & 30.9 \\
$2-3$ & 281 & 47.6 \\
$>=4$ & 127 & 21.5
\end{tabular}

Birth interval $(n=416)$

$\begin{array}{lll}<24 \text { months } & 105 & 25.2 \\ 24-47 \text { months } & 131 & 31.5 \\ >=48 \text { months } & 180 & 43.3\end{array}$

Antenatal care $(n=590)$

$\begin{array}{ll}\text { Yes } & 579 \\ \text { No } & 11\end{array}$

ANC visits $(n=581)$

$$
1-3
$$$$
>=4
$$

Home

Postpartum duration $(n=590)$

$\begin{array}{ll}0-12 \text { Weeks } & 186 \\ \text { 13-26 Weeks } & 198 \text { Weeks } \\ \text { 39-52 Weeks } & 141 \\ \text { ostnatal care }(n=590) & 65\end{array}$

Yes 258

No 332

Who decide to use FP $(n=590)$

Mainly respondents 104

Mainly husband 36

Jointly decision

97.8

Postpartum menstruation status $(n=590)$

Menstruating

Amenorrhea 385

Resumed sexual intercourse $(n=590)$

Yes

68.3

31.7
Table 2 Characteristics of maternal and reproductive health services use in Aksum town, Tigray region, northern Ethiopia, June, 2015 ( $n=590)$ (Continued)

\begin{tabular}{lll}
\hline Variables & Frequency $(\mathrm{n})$ & Percentage $(\%)$ \\
\hline Reproductive intention $(n=590)$ & & \\
Want to have space & 396 & 67.1 \\
Want to limit & 86 & 14.6 \\
Undecided & 99 & 16.8 \\
Want to have a child soon & 9 & 1.5 \\
\hline
\end{tabular}

\section{Factors associated with intention to use modern} contraceptive

The multivariable logistic regression model showed that, resumed sexual intercourse, husband family planning approval, knew at least one modern contraceptive were found significantly associated with the dependent variable.

Women who were resumed sexual intercourse at the time of survey $(\mathrm{AOR}=1.78 ; 95 \% \mathrm{CI}$ : $1.34,3.92$ ] had higher odds of intention on modern contraceptives compare to women who were not resumed sexual intercourse. There was significantly association of intention to utilize methods of contraceptive among women who their husband approved family planning to use $(\mathrm{AOR}=1.57$; $95 \%$

Table 3 Knowledge and practice of modern contraceptives of postpartum women in Aksum town, Tigray region, northern Ethiopia, June, $2015(n=590)$

\begin{tabular}{lcl}
\hline Variables & Frequency $(\mathrm{n})$ & Percentage (\%) \\
\hline Know at least one modern contraceptive & \\
Yes & 564 & 95.6 \\
No & 26 & 4.4 \\
Type of modern contraceptives known & \\
Injectable & 512 & 86.8 \\
Pills & 407 & 69.0 \\
Implants & 406 & 68.8 \\
IUD & 285 & 48.3 \\
Male condom & 120 & 20.3 \\
Female sterilization & 44 & 7.5 \\
Male sterilization & 24 & 4.1
\end{tabular}

Heard contraceptive massage in the last 12 months(mass media, print media)

$\begin{array}{lll}\text { Yes } & 564 & 95.6 \\ \text { No } & 26 & 4.4\end{array}$

Use of modern contraceptives

$\begin{array}{lll}\text { Yes } & 283 & 48.0 \\ \text { No } & 307 & 52.0\end{array}$

Intend to use contraceptive methods $\left(\mathrm{n}=258^{\mathrm{a}}\right)$

$\begin{array}{lll}\text { Yes } & 258 & 84.3 \\ \text { No } & 49 & 15.7\end{array}$

a(Among currently not used contraceptive) 
CI: 2.02, 5.57) compares to their counterparts. Those women who were know at least one method of modern contraceptive have 5.17 times higher odds to intention to use modern contraceptive during extended postpartum period compare to their counterparts $(A O R=5.17 ; 95 \%$ CI: 1.69,15.82) (Table 4).

\section{Discussion}

In this study the prevalence of intention to use on modern contraceptive among postpartum women was $84.3 \%$. This result was slightly lower than the finding in United State of America which reported [90\%] [9]. This variation could be explained by the difference of study setting, accesses to information and availability to services use.

Two hundred fifteen (83.3\%) and $16.7 \%$ of the postpartum women want to space and to limit respectively. Moreover, their intention on contraceptive methods was adequate. This tell us, the skilled attendants and family planning providers needs to evaluate the reproductive goal of the women during postpartum period and inform them the availability contraceptive methods during postnatal follow up and immunization period. This could be due to the current the government tireless working to improve the knowledge and practice of contraceptive using different strategies (i.e. availing different contraceptive with free of charge, community based contraceptive distribution and providing information using media outlets) and economic burden condition.

More than $95 \%$ of the study participants were mentioned at least one modern contraceptive. This result was in line a study conducted in Ethiopia. This finding might be explained by the fact that due to the efforts done by the Ethiopian government health policy and non government organizations (NGOs) to strengthen for maternal health and family health strategies like: the different community and institutional-based reproductive health services and health education being given by health workers, introducing health development army (HDA) and community health insurance have a positive effect for the increasing knowledge level of family planning [14].

The most well known modern contraceptive methods were injectable and pills. Among all postpartum women, the permanent contraceptives were least known (Table 3). This was in line the finding in Ethiopia [24, 28].

Women who were resumed sexual intercourse at the time of survey key predictors on intending to use methods of contraceptive. This may be due to when women resume sexual intercourse; they perceive themselves to be at high risk for pregnancy, which motivates them to use contraceptive methods in the future. Therefore, resuming sexual intercourse is strongly linked to the intention of contraceptive methods in the extended postpartum period (EPP) [5].

Table 4 Factors associated with intention to use modern contraceptive methods in the future among postpartum women, in Aksum town, Tigray region, northern Ethiopia, June, 2015

\begin{tabular}{|c|c|c|c|c|}
\hline \multirow[t]{2}{*}{ Variables } & \multicolumn{2}{|c|}{ Intention to use contraceptives } & \multirow[t]{2}{*}{$\operatorname{COR}(95 \% \mathrm{Cl})$} & \multirow[t]{2}{*}{$\mathrm{AOR}(95 \% \mathrm{Cl})$} \\
\hline & Yes (\%) & No (\%) & & \\
\hline \multicolumn{5}{|l|}{ Parity } \\
\hline $1-4$ & 226(84.9) & $40(15.1)$ & $1.41(1.34,3.28)$ & $2.31(0.82,2.93)$ \\
\hline$>=5$ & $32(80)$ & $8(20)$ & 1 (ref) & 1 (ref) \\
\hline \multicolumn{5}{|l|}{ Menses status } \\
\hline Resumed & 40(81.6) & $9(18.4)$ & $1.25(1.12,2.79)$ & $1.22(0.45,3.28)$ \\
\hline Not resumed & 218(84.8) & $39(15.2)$ & 1 (ref) & 1 (ref) \\
\hline \multicolumn{5}{|c|}{ Resumed sexual intercourse } \\
\hline Yes & 115(83.3) & $23(16.7)$ & $1.14(1.12,2.12$ & $1.78(1.34,3.92)$ \\
\hline No & $143(85.1)$ & 25(14.9) & 1 (ref) & 1 (ref) \\
\hline \multicolumn{5}{|c|}{ Ever discussed with husband regarding FP } \\
\hline Yes & 192(92.3) & $16(7.7)$ & $4.80(2.31,9.93)$ & $2.27(0.62,8.31)$ \\
\hline No & $50(71.4)$ & $20(28.6)$ & 1 (ref) & 1 (ref) \\
\hline \multicolumn{5}{|c|}{ Husband FP approval } \\
\hline Yes & 183(92) & 16(8) & $3.87(1.88,7.96)$ & $1.57(2.02,5.57)$ \\
\hline No & $59(74.7)$ & $20(25 . .3)$ & 1 (ref) & 1 (ref) \\
\hline \multicolumn{5}{|c|}{ Know at least one modern contraceptive } \\
\hline Yes & $248(87.3)$ & $36(12.7)$ & $8.26(3.33,20.51)$ & $5.17(1.69,15.82)$ \\
\hline No & 10(45.5) & 12(54.5) & 1 (ref) & 1(ref) \\
\hline
\end{tabular}

Ref: Reference Category 
There was significantly associated with intention to use methods of contraceptive among women who were their husband approved family planning to use. This finding indicated that the importance of focusing on male involvement in family planning efforts because husband / partner do seem to play a key role in deciding future contraceptive methods for their wives $[29,30]$.

Study participants who knew at least one modern contraceptive method had more likely of intention to use contraceptive methods compared to those who did not knew any methods of contraceptive. This in line a study conducted in Adigrat town, Tigray region, Ethiopia [11].

\section{Limitations}

This study used a cross-sectional study, which can only showed association rather than causal relationships between the different independent variables and the dependent variable. The findings from this study are internally and externally valid and provide a clear picture of the situation on intention on modern contraceptive use among postpartum women in Aksum town.

\section{Conclusion and recommendation}

More than eight in ten study participants have intention to use contraceptive in the Aksum town. The factors affecting intention to use modern contraceptive method were resumed sexual intercourse; postpartum women who were their husband approved family planning to use and knew at least one type of modern contraceptive. Therefore, this study recommend that; in order to increase intention and use of contraceptive, the family planning services providers \& programmers should continue the promotion of husband / partner involvement and family planning knowledge through printed media and mass media. In addition, the town administrative health office should design health education programs that promote contraceptive knowledge and practice during extended postpartum period.

\section{Additional file}

Additional file 1: Figure S1. Schematic representation of sampling procedure, intention on contraceptive use and associated factors among postpartum women in Aksum town, Tigray region, northern Ethiopia, June $2015(n=604)$. (DOCX $17 \mathrm{~kb})$

\footnotetext{
Abbreviations

AOR: Adjusted odds ratio; Cl: Confidence interval; COR: Crude odds ratio; EPP: Extended postpartum period; FP: Family planning; HAD: Health development army; HEW: Health extension worker; IRB: Institutional review board; IUD: Intrauterine devices; MCH: Maternal and child health; MPH: Master of public health; NGOs: Non government organizations; PNC: Postnatal care; SDGs: Sustainable development goals; SPSS: Statistical package for the social sciences; VIF: Variance inflation factor
}

\section{Acknowledgments}

The authors would like to acknowledge to all study participants, data collectors and supervisors.

\section{Consent for publication}

This manuscript does not contain any individual person's data in the form of image or video. Hence consent for publication is not applicable.

\section{Funding}

This study did not receive any specific grant from funding agencies or institutions in the public, commercial, or not-for-profit sectors.

\section{Availability of data and materials}

The datasets upon which analysis and conclusions were made are available and will be offered upon reasonable request.

\section{Authors' contributions}

THA wrote the proposal, participated in the data collection, in the statistical analysis, interpretation and writing the manuscript. HSB \& GMW participated in data analysis and writing the methodology section. All authors critically revised the manuscript and made substantial contributions to the final draft. All authors THA, HSB and GMW read and approved the final manuscript.

\section{Ethics approval and consent to participate}

This study protocol was granted by the Institutional Review Board (IRB) of the Institute of Public Health, University of Gondar. Informed written consent was obtained from each study participants to confirm willingness for participation after explaining the objective of the study. Participants were assured of privacy and confidentiality and informed consent was secured from all participants after the study had been explained.

\section{Competing interests}

The authors declare that they have no competing interests.

\section{Publisher's Note}

Springer Nature remains neutral with regard to jurisdictional claims in published maps and institutional affiliations.

\section{Author details}

${ }^{1}$ Department of Reproductive Health, School of Public Health, College of Health Sciences, Aksum University, P.O. Box: 298, Aksum, Tigray, Ethiopia. ${ }^{2}$ Department of Epidemiology and Biostatistics, School of Public Health, College of Health Sciences, Aksum University, Aksum, Tigray, Ethiopia.

Received: 17 March 2018 Accepted: 28 October 2018

Published online: 09 November 2018

\section{References}

1. Singh S, Darroch JE. Adding it up: Costs and benefits of contraceptive services: Guttmacher Institute and UNFPA; 2012

2. Cleland J, Bernstein S, Ezeh A, Faundes A, Glasier A, Innis J. Family planning: the unfinished agenda. Lancet. 2006;368(9549):1810-27.

3. Starbird E, Norton M, Marcus R. Investing in family planning: key to achieving the sustainable development goals. Global Health: science and. Practice. 2016:4(2):191-210.

4. Roy T, Ram F, Nangia P, Saha U, Khan N. Can women's childbearing and contraceptive intentions predict contraceptive demand? Findings from a Iongitudinal study in Central India. Int Fam Plan Perspect. 2003:25-31.

5. Ross JA, Winfrey WL. Contraceptive use, intention to use and unmet need during the extended postpartum period. Int Fam Plan Perspect. 2001:20-7.

6. WHO, MCHIP, World Bank, FIGO, Jhpiego, UNFPA, et al. Statement for Collective Action for Postpartum Family Planning. 2012.

7. McKaig C, Chase R. Postpartum family planning technical consultation-meeting report. Washington, DC: JHPIEGO, Baltim ore, Maryland; 2007.

8. World Health Organization. Programming strategies for postpartum family planning. 2013.

9. Weisband YL, Keder LM, Keim SA, Gallo MF. Postpartum intentions on contraception use and method choice among breastfeeding women attending a university hospital in Ohio: a cross-sectional study. Reprod Health. 2017;14(1):45. 
10. Idowu A, Deji S, Ogunlaja O, Olajide S. Determinants of intention to use post partum family planning among women attending immunization clinic of a tertiary hospital in Nigeria. Am J Public Health Res. 2015;3(4):122-7.

11. Gebremariam A, Addissie A. Intention to use long acting and permanent contraceptive methods and factors affecting it among married women in Adigrat town, Tigray, Northern Ethiopia. Reprod Health. 2014;11(1):24.

12. Abraha TH, Teferra AS, Gelagay AA. Postpartum modern contraceptive use in northern Ethiopia: prevalence and associated factors. Epidemiol Health. 2017;39: e2017012.

13. Abraha TH, Gebrezgiabher BB, Aregawi BG, Belay DS, Tikue LT, Welay GM. Predictors of postpartum contraceptive use in rural Tigray region, northern Ethiopia: a multilevel analysis. BMC Public Health. 2018;18(1):1017.

14. Federal Democratic Republic of Ethiopia [FDRE]. Ministry of Health[MoH]. Health Sector Transformation Plan[HSTP]. 2015/16-2019/20, Addis Ababa, Ethiopia. 2015.

15. Meskele M, Mekonnen W. Factors affecting women's intention to use long acting and permanent contraceptive methods in Wolaita zone, southern Ethiopia: a cross-sectional study. BMC Womens Health. 2014;14(1):109.

16. Abajobir A. Intention to use long-acting and permanent family planning methods among married 15-49 years women in Debremarkos Town, Northwest Ethiopia. Fam Med Med Sci Res. 2014;3(145):2.

17. Tekelab T, Sufa A, Wirtu D. Factors affecting intention to use long acting and permanent contraceptive methods among married women reproductive age groups in Western Ethiopia: a community based cross sectional study. Fam Med Med Sci Res. 2015;4(158):2.

18. Dibaba Y. Factors influencing women's intention to limit child bearing in Oromia, Ethiopia. Ethiop J Health Dev. 2009;23(1).

19. Aksum town health office. Aksum town health office report, Tigray Region, Ethiopia. 2015

20. Lemeshow S, Hosmer D Jr, Klar J, Lwanga S. Adequacy of sample size in health sciences. New York: Wiley; 1990.

21. Hajian-Tilaki K. Sample size estimation in epidemiologic studies. Caspian J Intern Med. 2011:2(4):289.

22. Rutstein SO, Rojas G. Guide to DHS statistics. Calverton: ORC Macro; 2006.

23. Rutstein SO. Effects of preceding birth intervals on neonatal, infant and under-five years mortality and nutritional status in developing countries: evidence from the demographic and health surveys. Int I Gynecol Obstet. 2005;89:S7-S24

24. Central Statistical Agency (CSA) [Ethiopia] and ICF. Ethiopia Demographic and Health Survey 2016. Addis Ababa, Ethiopia, and Rockville, Maryland, USA: CSA and ICF; 2016.

25. Center for Disease Control and Prevention(CDC). https://www.cdc.gov/ epiinfo/support/userguide.html.

26. Forthofer RN, Lee ES, Hernandez M. Biostatistics: a guide to design, analysis and discovery: Elsevier; 2006.

27. Hosmer DW Jr, Lemeshow S, Sturdivant RX. Applied logistic regression: Wiley; 2013

28. Central Statistical Agency (CSA) [Ethiopia] and ICF. Ethiopia Demographic and Health Survey 2011. Addis Ababa, Ethiopia, and Rockville, Maryland, USA: CSA and ICF: 2011.

29. Kassa M, Abajobir AA, Gedefaw M. Level of male involvement and associated factors in family planning services utilization among married men in Debremarkos town, Northwest Ethiopia. BMC Int Health Hum Rights. 2014:14(1):33.

30. Vouking MZ, Evina CD, Tadenfok CN. Male involvement in family planning decision making in sub-Saharan Africa-what the evidence suggests. Pan Afr Med J. 2014:19.

Ready to submit your research? Choose BMC and benefit from:

- fast, convenient online submission

- thorough peer review by experienced researchers in your field

- rapid publication on acceptance

- support for research data, including large and complex data types

- gold Open Access which fosters wider collaboration and increased citations

- maximum visibility for your research: over $100 \mathrm{M}$ website views per year

At BMC, research is always in progress.

Learn more biomedcentral.com/submissions 